\title{
3 Research Square

\section{Uncertainty Analysis of Hydrological Drought due to Record Length, Time Scale, and Probability Distribution Functions Using Monte-Carlo Simulation Method}

\section{Faezeh Ghasemnezhad}

Yasouj University

Ommolbanin Bazrafshan ( $D$ o.bazrafshan@hormozgan.ac.ir)

Hormozgan University

Mehdi Fazeli

Yasouj University

Mohammad Parvinnia

Yasouj University

Vijay Singh

Texas A\&M University

\section{Research Article}

Keywords: Uncertainty, Standardized Precipitation Index, Probability Distribution

Posted Date: January 15th, 2021

DOI: https://doi.org/10.21203/rs.3.rs-131396/v1

License: (c) (1) This work is licensed under a Creative Commons Attribution 4.0 International License.

Read Full License 


\title{
Uncertainty Analysis of hydrological Drought due to Record Length, Time
}

\author{
Scale, and Probability Distribution Functions Using Monte-Carlo
}

\author{
Simulation Method
}

\author{
Faezeh Ghasemnezhad $^{1}$, Ommolbanin Bazrafshan ${ }^{2 *}$, Mehdi Fazeli ${ }^{1}$, Mohammad Parvinnia $^{1}$, \\ Vijay P. Singh ${ }^{3}$ \\ 1- Department of Water Resource Management and engineering, Faculty of Civil Engineering, University of \\ Yasuj, Yasuj, Iran. \\ 2- Department of Natural Resources Enginnering, Faculty of Agricultural and Natural Resources, University of \\ Hormozgan, Bandar Abbas, Iran (*Corresponding Author: O.bazrafshan@ hormozgan.ac.ir) \\ 3- Professor, Department of Biological and Agricultural Engineering and Zachry, Department of \\ Civil Engineering, Texas A\&M University, College Station, TX, USA.
}

\begin{abstract}
Standardized Runoff Index (SRI), as one of the well-known hydrological drought indices, may contain uncertainties caused by the employment of the distribution function, time scale, and record length of statistical data. In this study, the uncertainty in the SRI estimation of monthly discharge data of 30 and 49 year length from Minab dam watershed, south of Iran, was investigated. Four probability distribution functions (Gamma, Weibull, Lognormal, and Normal) were used to fit the cumulative discharge data at 3, 6. 9, 12, 24 and 48 month time scales, with their goodness-of-fit and normality evaluated by K-S and normality tests, respectively. Using Monte-Carlo sampling, 50,000 statistical data were generated for each event and each time scale, followed by $95 \%$ confidence interval. The width of the confidence interval was used as uncertainty and sources of uncertainty were investigated using miscellaneous factors. It was found that the maximum uncertainty was related to normal and lognormal distributions and the minimum uncertainty to gamma and Weibull distributions. Further, the increase in both time scale and record length led to the decrease in uncertainty.
\end{abstract} Keywords: Uncertainty, Standardized Precipitation Index, Probability Distribution 


\section{1-Introduction}

Drought, basically caused by reduction in precipitation, may occur in both high and lowrainfall areas of the globe. It is observed that in the recent decades drought intensity has increased and the time period between severe droughts has decreased, which are related to climate change (Mishra and Singh 2010).

Standardized Precipitation Index (SPI) (McKee et al. 1993) has been widely used for meteorological drought monitoring. A similar index, called the Standardized Runoff Index (SRI), is used for hydrological drought characterization (Shukla and Wood 2008). SRI, like SPI, has some advantages, as for instance, the capability to compare spatial positions of regions, the flexibility of using different time scales, non-complexity in calculations, the ease of obtaining the required information (for SPI: precipitation data and for SRI: discharge data) (Guttman 1998; Lloyd-Hughes and Saunders 2002). It also has negative points, such as the problem of finding appropriate distribution functions to simulate the observed precipitation series (Wu et al. 2007; Angelidis et al. 2012; Guttman 1999) and the need for long time series for attaining reliable validity (Guttman 1999, 1994; Wu et al. 2005). The type of probability distribution function used highly impacts the SRI calculation. For instance, the choice of an inappropriate distribution function can lead to overestimation or underestimation of drought intensity, error in realizing the start and end of drought, and miscalculation of drought duration (Sienz et al. 2012). This is the first source of uncertainty, because the use of different distributions to illustrate precipitation data series results in different values of SRI (Guttman 1999).

Two-parameter gamma distribution is often useful for monthly and seasonal precipitation data and has been widely used (Ropelewski et al. 1985; Wilks and Eggleston 1992; McKee et al. 1993). 
Another source of uncertainty has been shown by length and the variety of rainfall records used to fit the probability. This has been the case among other researchers, such as Guttman (1994) and Wu et al. (2005) on the need for accurate estimation of SPI estimates, with data of different lengths. For this purpose, the minimum time series is considered to be a 30 -year time series, but it is recommended by the (WMO, 2012) time series of 50 or 60 years. In addition, with the same time series length, rainfall variability affects the SPI confidence limits. That is, the higher the variability of precipitation, the greater the uncertainty. This aspect can be observed for the same station with the change of moon and time scale.

Some studies employed a bootstrap technique to analyze uncertainty intervals caused by the distribution function, time scale, and length of time series (Guttman 1994; Wu et al. 2005; Vicente-Serrano et al. 2010; Hong et al. 2015; Vergni et al. 2015; Hu et al. 2015).

This study aims to assess the sources of uncertainty in hydrological drought using Monte Carlo stochastic data generation, due to different probability distribution functions and time scales at Minab hydrometric station for two 49 and 30 years of record lengths.

Due to these outstanding cases with implementation SPI, this study is designed to standardize SPI method, with introduction and use a more sensitive statistical test for the probability of candidates distributions used to normalize these drought indices. Objectives (1) more information is needed to highlight careful testing of the assumed distributions for SPI (2) to provide several improvements SPI method, and (3) relative presentation comparison of several common distributions used for normalization SPI with general distribution advice.

\section{2- Materials and methods}

\section{2-1 Case study}

The study region, Minab Dam Watershed having 856.95 square kilometers of area, is located $70 \mathrm{~km}$ east of Bandar Abbas City, adjacent to Hormoz Strait, south of Iran. It is limited to $26^{\circ}$ $96^{\prime} \mathrm{N}-27^{\circ} 40^{\prime} \mathrm{N}$ latitudes and $56^{\circ} 78^{\prime} \mathrm{E}-57^{\circ} 13^{\prime} \mathrm{E}$ longitudes. Possessing a mild steep, this 
watershed links the western parts of Mokran geological formations to the Persian Gulf beach and is surrounded by soil foothills.

\section{2-2 Required Data}

Minab Hydrometric Station at the upstream side of Minab Dam is active since 1966. The statistical properties of the station for 30 and 49 years long time series are shown in table 1. Further, the Hurst test and Return test were used to examine the sufficiency and homogeneity of data respectively, as shown in table 1 .

Table 1- Statistical characteristics of case study

\begin{tabular}{ccccccccc}
\hline $\begin{array}{c}\text { Sampling } \\
\text { length }\end{array}$ & Mean & SD & Max & Min & Skewness & Kurtosis & $\begin{array}{c}\text { Hurst } \\
\text { statistic }\end{array}$ & $\begin{array}{c}\text { Return } \\
\text { point }\end{array}$ \\
\hline $\begin{array}{c}1966-67 \text { to } \\
2014-15\end{array}$ & 8.62 & 7.69 & 35.3 & 0.62 & 1.82 & 3.57 & $0.8^{*}$ & $0.77^{*}$ \\
$\begin{array}{c}1985-86 \text { to } \\
2014-2015\end{array}$ & 6.71 & 6.37 & 31.9 & 0.62 & 2.37 & 7.69 & $0.73^{*}$ & 0.29 \\
\hline
\end{tabular}

*Significant at $99 \%$ level

\section{2-3 Standardized runoff index (SRI) and drought characteristics}

To study meteorological drought, several indexes have been proposed, of which Standardized precipitation index (SPI) (McKee et al. 1993) is more commonly used. Regarding hydrological drought, two well-known indexes, mainly Palmer hydrological drought severity index (PHDSI) and surface water supply index (SWSI) have been proposed, but were difficult to use because of the need for numerous and partly complicated calculations. To simplify, similar to SPI, standardized runoff index (SRI) index was introduced, based on monthly discharge data. The basic steps to calculate SRI are as follows: First, an appropriate distribution is fitted to monthly discharge values of each station and cumulative probabilities are calculated. Some studies suggest a gamma distribution for small watersheds and normal or two-variable log-normal distribution for large basins as the best fitting distributions for monthly discharge data. Second, co-probability transfer from cumulative fitted distribution to cumulative normal standard distribution is performed. Then, the corresponding SRI of a specific discharge is defined as the value of the normal standard variable for which the 
cumulative probability is equal to that of the fitted distribution (Nalbantis and Tsakiris, 2008; Shukla and Wood 2008).

The characteristics of drought in this study are intensity and duration. Drought duration is defined as the length of a time period having SRI values less than zero continuously (Vasiliades et al. 2011). The cumulative indexes through the drought duration is summarized to obtain drought intensity. For ease, the drought intensity is considered as an absolute value as follows:

$S=\left|\sum_{i=1}^{D} S R I_{i}\right|$

in which $\mathrm{S}$ is the drought intensity, and $\mathrm{D}$ is the number of the consecutive drought periods.

\section{2-4 Fitting the best statistical distribution function to discharge data and applying normality test for calculated SRI}

In order to determine the most appropriate statistical distribution function for a specific time scale and station, the Kolmogrov-Smirnov (K-S) test was employed. The K-S statistic is obtained, based on the maximum frequency difference between empirical and theoretical distribution functions as:

$\mathrm{D}=\max |\mathrm{F}(\mathrm{x})-\hat{\mathrm{F}}(\mathrm{x})|$

in which $\mathrm{F}$ is the real cumulative relative frequency, and $\widehat{\mathrm{F}}$ is the expected cumulative relative frequency. If $D$ is less than the critical value $D_{\alpha}$ then the null hypothesis $\left(H_{0}\right)$ is accepted. Here $\mathrm{H}_{0}$ hypothesis is no significant difference between empirical and theoretical values. In this study the K-S test at $95 \%$ confidence level (or $5 \%$ error level) was examined (Naghettini 2017). As another criterion, if p-value is less than 0.05 the corresponding function is not desirable.

Another method for goodness-of-fit evaluation of SPI values is the normality test which is used for SRI data in the current study (Wu et al. 2007). The normality degree would decline 
when the ratio of zero values in initial data was high. Furthermore, a weak fitting of selective distribution function could lead to non-normality in the SPI time series (Wu et al. 2007).

\section{2-5 Determining SRI confidence intervals and uncertainty analysis using Monte Carlo}

\section{method}

Resampling Monte Carlo Method (MCM) was used for uncertainty analysis. MCM is classified among those calculation algorithms for which their results are obtained, based on stochastic sample iteration. This method is often used in physical simulation, mathematical systems, commercial risk assessment, and uncertainty evaluation of measurements in testing and calibration laboratories. Calculations of this method are commonly done on computers and its application is best justified when descriptive methods are not responsible for the evaluation and analysis of phenomena with different inputs and outputs or their results are not so reliable.

MCM was employed for different time scales ( $K=3,6,9,12,24,48$ months), different years $(j=1966,1967, \ldots, 2014)$, and different months $(i=1,2, \ldots, 12)$. The next steps of MCM were as follows:

1- Using Latin Hypercube Sampling (LHS) to generate a number of 50000 stochastic discharge sample for each $x_{i, j}^{k}$ according to the probability density function (here: Normal).

2- Fitting an appropriate distribution function to the generated data.

3- Calculating the cumulative probability $P\left(x_{i, j}^{k}\right)$ for the $x_{i, j}^{k}$ values and changing it to standard normal values (SRI) similar to the SPI calculation.

4- Analyzing the upper and lower limits for $95 \%$ confidence level, including $97.5 \%$ $\left(1-\frac{\alpha}{2}\right)$ and $2.5 \%\left(\frac{\alpha}{2}\right)$ percentiles.

For more clarity, some of the steps are shown via an example in Figures 1 (a) and (b), which involves determining SRI interval confidence for discharge values. For instance, $X_{2013-14-2}^{6}$ 
(discharge during 2013-2014, 6 month time scale, in February) was found as 8.563 cubic meters per seconds in the recorded data. For each discharge value of year $i$, month $\mathrm{j}$, and time scale k, 50000 stochastic discharge data were generated, then the gamma distribution function was fitted to data, cumulative co-probable transform from gamma to normal distribution function was executed, SRI value was calculated, upper and lower limits for $95 \%$ confidence interval were evaluated. The calculated cumulative probability was 0.259 and 0.75 and SRI values were -0.64 and 0.69 for lower and upper limits, respectively (Figure 1).

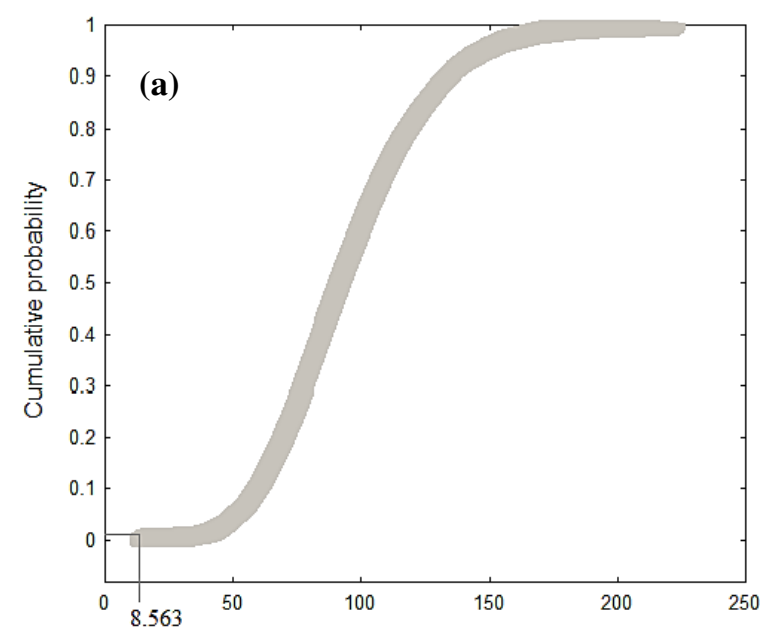

Discharge Cumulative precipitation

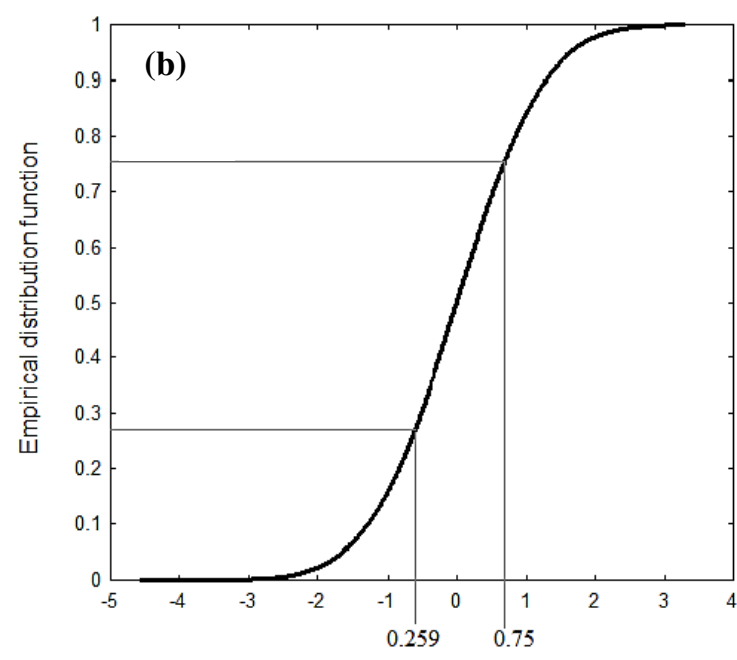

$(\mathrm{SRI}=-0.64) \quad(\mathrm{SRI}=0.69)$

SRI Cumulative probability

Figure 1- Representation of some steps required to obtain a confidence.

The interval for SRI by a Monte- Carlo procedure. Example concerning the station of Minab, the time scale $\mathrm{k}=6$ months, the month $\mathrm{j}=2$, and the discharge value $\mathrm{X}=8.563 \mathrm{~m} 3 / \mathrm{s}$. (a) The $\mathrm{M}(\mathrm{M}=50000)$ gamma cumulative distribution functions (fitted to each sample Monte- Carlo from the original discharge data), and $\mathrm{M}$ possible values of cumulative probability $\mathrm{P}$ $\left(X_{2013-14-2}^{6}\right)$ are estimated, (b) the empirical cumulative distribution function of the M values of $P\left(X_{i, j}^{k}\right)$, and the 0.25 th $\mathrm{P}\left(X_{i, j}^{k}\right)=0.259$ and 0.75 th $\mathrm{P}\left(X_{i, j}^{k}\right)=0.75$ percentile detected. The standard normal variates corresponding to these cumulative probabilities are respectively the lower $(\mathrm{SRI}=-0.64)$ and upper $(\mathrm{SRI}=0.69)$ limits of the SRI confidence interval $(\mathrm{P}=95 \%)$

\section{3- Results and discussion}

\section{3-1 Goodness-of-fit and normality test results}


Table 2-Results of the Kolmogorov-Smirnov test (KS test) at the 0.05 significance level and the Normality test

\begin{tabular}{|c|c|c|c|c|c|c|c|c|c|}
\hline \multirow{2}{*}{$\begin{array}{l}\text { Time } \\
\text { Scale }\end{array}$} & \multicolumn{4}{|c|}{ K-S test } & \multirow{2}{*}{$\begin{array}{l}\text { Time } \\
\text { Scale }\end{array}$} & \multicolumn{4}{|c|}{ Normality test } \\
\hline & $\mathbf{G}$ & LN & $\mathbf{N}$ & $\mathbf{W}$ & & $\mathbf{G}$ & $\mathbf{L N}$ & $\mathbf{N}$ & $\mathbf{W}$ \\
\hline \multicolumn{10}{|c|}{ 49-years (1966-2015) } \\
\hline 3 & 0.96 & 0.013 & 0.027 & 0.017 & 3 & 0.971 & 0.89 & 0.76 & 0.62 \\
\hline 6 & 0.62 & 0.81 & 0.020 & 0.78 & 6 & 0.99 & 0.87 & 0.29 & 0.98 \\
\hline 9 & 0.59 & 0.73 & 0.019 & 0.75 & 9 & 0.998 & 0.69 & 0.46 & 1.21 \\
\hline 12 & 0.51 & 0.9 & 0.015 & 0.63 & 12 & 1.28 & 0.88 & 0.65 & 1.32 \\
\hline 24 & 0.96 & 0.025 & 0.013 & 0.103 & 24 & 1.27 & 1.23 & 0.85 & 1.0 \\
\hline 48 & 0.6 & 0.88 & 0.010 & 0.58 & 48 & 1.32 & 0.95 & 0.62 & 1.42 \\
\hline \multicolumn{10}{|c|}{ 30-years $(1985-2015)$} \\
\hline 3 & 0.98 & 0.013 & 0.012 & 0.84 & 3 & 0.98 & 0.772 & 0.718 & 0.977 \\
\hline 6 & 0.63 & 0.011 & 0.92 & 0.57 & 6 & 0.947 & 0.725 & 0.988 & 0.974 \\
\hline 9 & 0.63 & 0.017 & 0.013 & 0.59 & 9 & 0.958 & 0.679 & 0.910 & 0.976 \\
\hline 12 & 0.81 & 0.014 & 0.012 & 0.77 & 12 & 0.971 & 0.614 & 0.92 & 0.969 \\
\hline 24 & 0.12 & 0.013 & 0.015 & 0.702 & 24 & 0.91 & 0.638 & 0.956 & 0.99 \\
\hline 48 & 0.6 & 0.014 & 0.010 & 0.09 & 48 & 0.981 & 0.610 & 0.91 & 0.92 \\
\hline
\end{tabular}

G: Gamma Dist, LN: Lognormal Dist, N: Normal Dist, W: Weibull Dist; Note: The highlited boxs is significance at $95 \%$ level

Results of K-S and normality tests for two record lengths (30 and 49 years) are given in table (2). For long period (49-years) and gamma disytibuyion, according to the results of K-S test all time scales were significant and according to the normality test all time scales except 3month were significant. For Weibull and lognormal distributions, both K-S and Normality tests showed significant fitting for 6, 9, 12 and 48 month time scales. For normal distribution none of the time scales were significant. Finally, according to table (1) gamma and normal distributions showed the best and weakest fits. For a short period (30-year), most time scales were significant for the Weibull and gamma distributions. Mitigation of record length from 49 to 30 years resulted in a reduction of significance percentage for normal and lognormal distributions.

\section{3-2 Monitoring of drought using SRI}

Figure (2) shows the results of drought monitoring for 48-month time scale according to the discharge data for long (49-year) and short (30-year) time periods. Commonly, different distributions showed similar results for various time scales such that wet and dry years were 
estimated more or less identically. Among all cases, under-estimation (the highest drought intensity) was related to Lognormal function and over-estimation (the maximum non-drought intensity) was related to the normal distribution. As an example, for 49-year record length and 48-month time scale (Figure 2a) the extreme values of SRI were -3.24 and +2.94 estimated by lognormal and normal distributions, respectively. Furthermore, the estimated values from of the Gamma and Weibull distributions were very similar. Similar results were obtained for other time scales of 49-year record length as well as all time scales of 30-year record length.
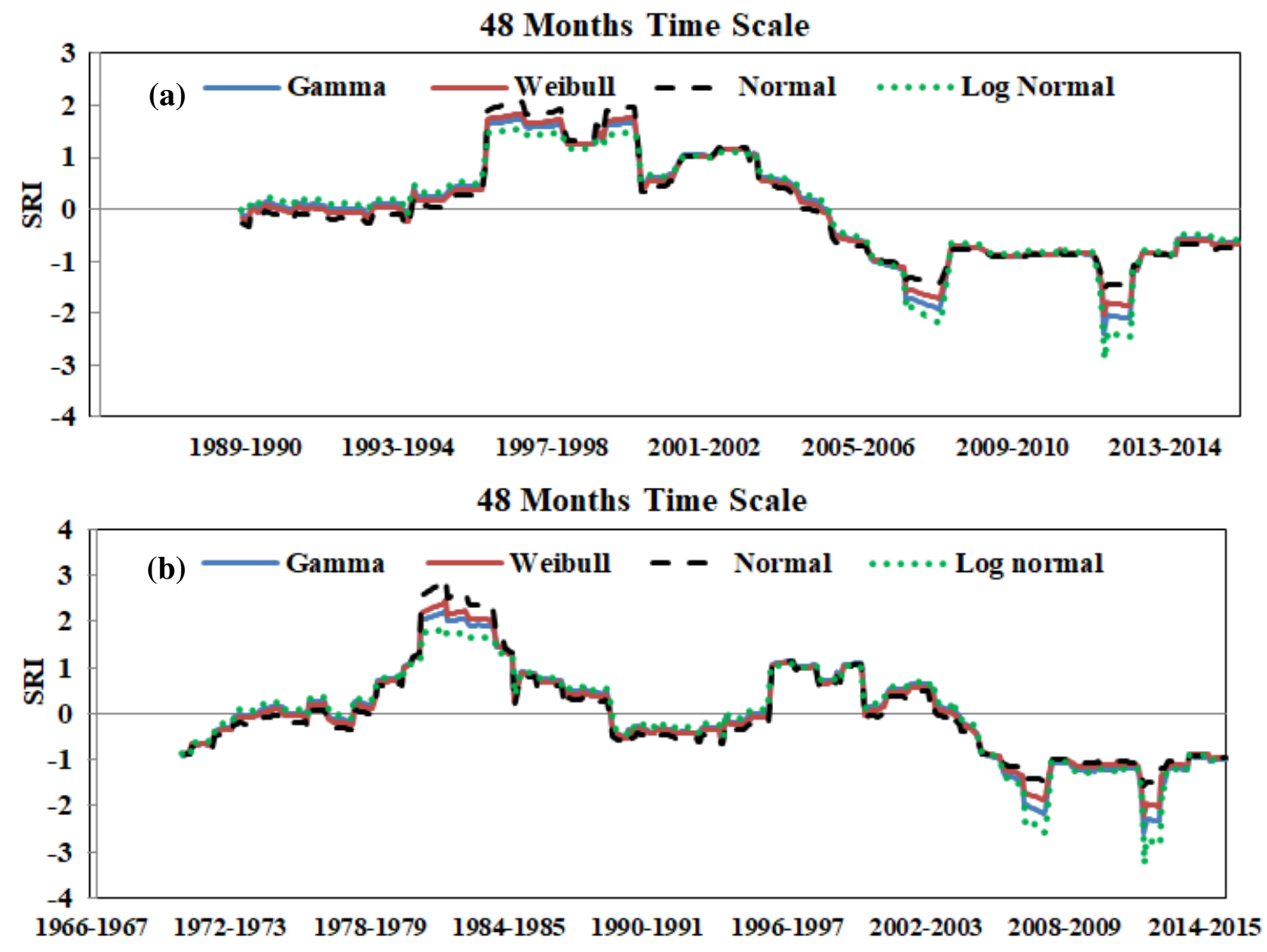

Figure 2 Drought monitoring using different probability distribution functions (a) 49 years and (b) 30 years 

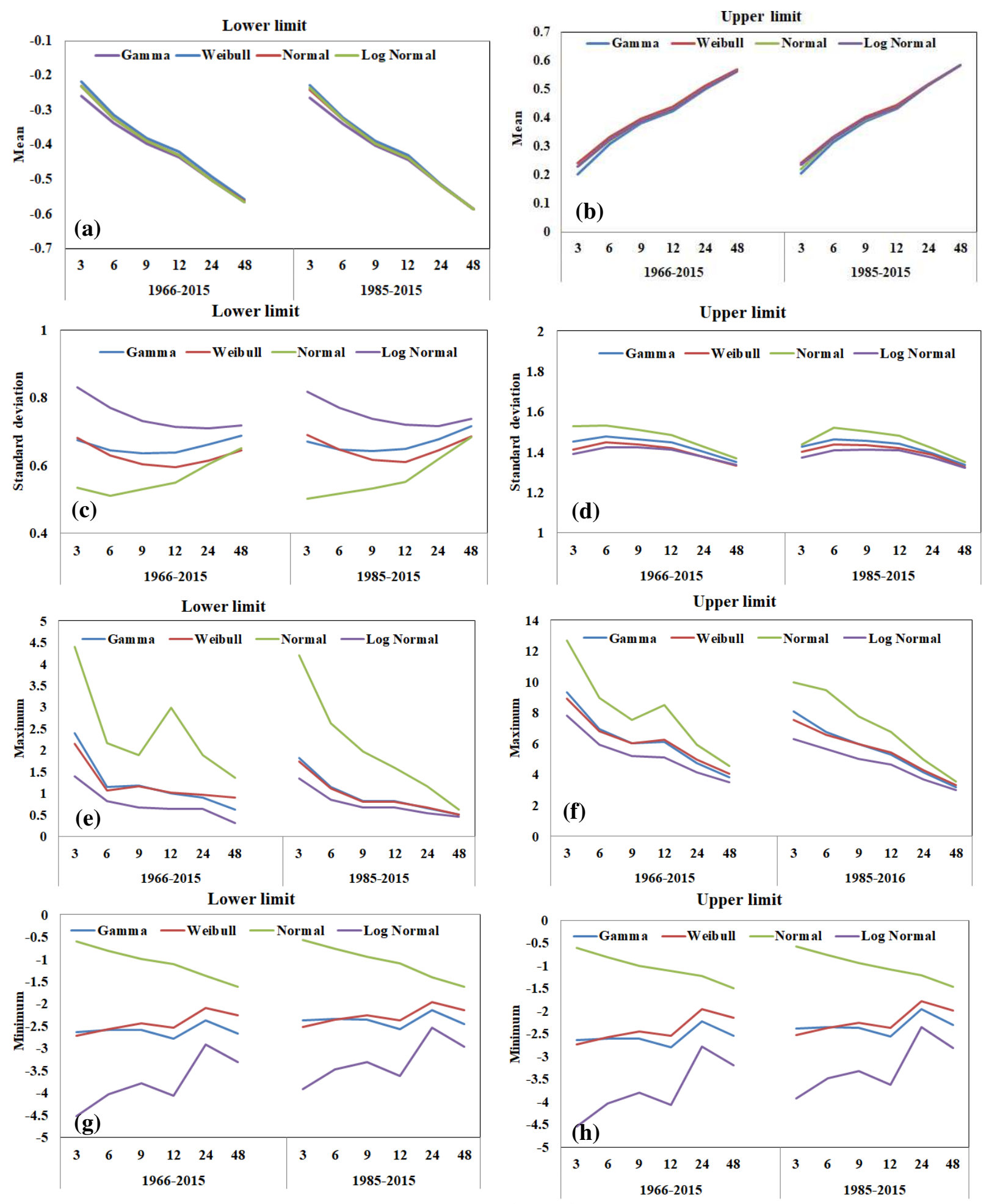

Figure 3- Average values of mean $(a, b)$ and standard deviation $(c, d)$ of maximum $(e, f)$ and minimum (g,h) of the size of the SRI 90\% confidence interval, varying the underlying probability distribution and the time scale $\mathrm{k}$ on the basis of the data of all stations and the complete time series (1964-65 to 2014-15) and (1986-2015)

\section{3-3 Influence of selective distribution function on drought monitoring}

In order to determine the upper and lower limits of the confidence interval, the SRI values for

3-48 month time scales were calculated; for the predefined confidence level, $95 \%$, the values 
of average, standard deviation, minimum, and maximum for the upper and lower limits were calculated. According to figure (3) the highest and lowest values of the above mentioned statistics for both 30- and 49-year record lengths were related to the normal and lognormal distributions, respectively.

Investigation of different time scales from 3 to 48 months for all distribution functions with the exception of the normal distribution showed that the increase in time scale resulted in the increase of absolute values of average and maximum and the decrease of absolute values of minimum values. Further, the highest and lowest curves were related to the normal and lognormal distributions, respectively (Figure 3). No significant difference was seen between long and short record lengths. Some studies propose that 40 to 60 years of data are needed for the stable estimation of statistics and 70 to 80 years of data is required for stable assessment of SPI confidence limits (Guttman et al. 1994).

\section{3-4 Drought assessment of specified confidence limits and distribution functions}

The aim of this section was to estimate the uncertainty in the SRI estimation. Graphical analysis of SRI time series shown as upper and lower limits could reveal some information about this uncertainty. For instance, Figure 4 displays the results of SRI values as well as 95\% confidence interval for 48-month time scale and 30- and 49-year time series. To avoid complexity, the display period was limited to 2010-2015 and the results of August 2012 was shown for all distribution functions.

As shown in figure 4, for August 2012 the upper and lower limits from the gamma distribution function were $(-2.54,-2.66)$ for 30 -years and $(-2.29,-2.46)$ for 49 years which were classified as extreme drought. Limits from other distribution functions showed consistency in drought classification. Estimations from the gamma and Weibull distributions showed no significant differences, while the upper and lower limits of the lognormal 
distribution $(-3.19,-3.31)$ estimated the highest drought intensities but the normal distribution with $(-1.48,-1.61)$ limits revealed the lowest drought values as moderate and severe droughts, respectively (McKee et al. 1993). 

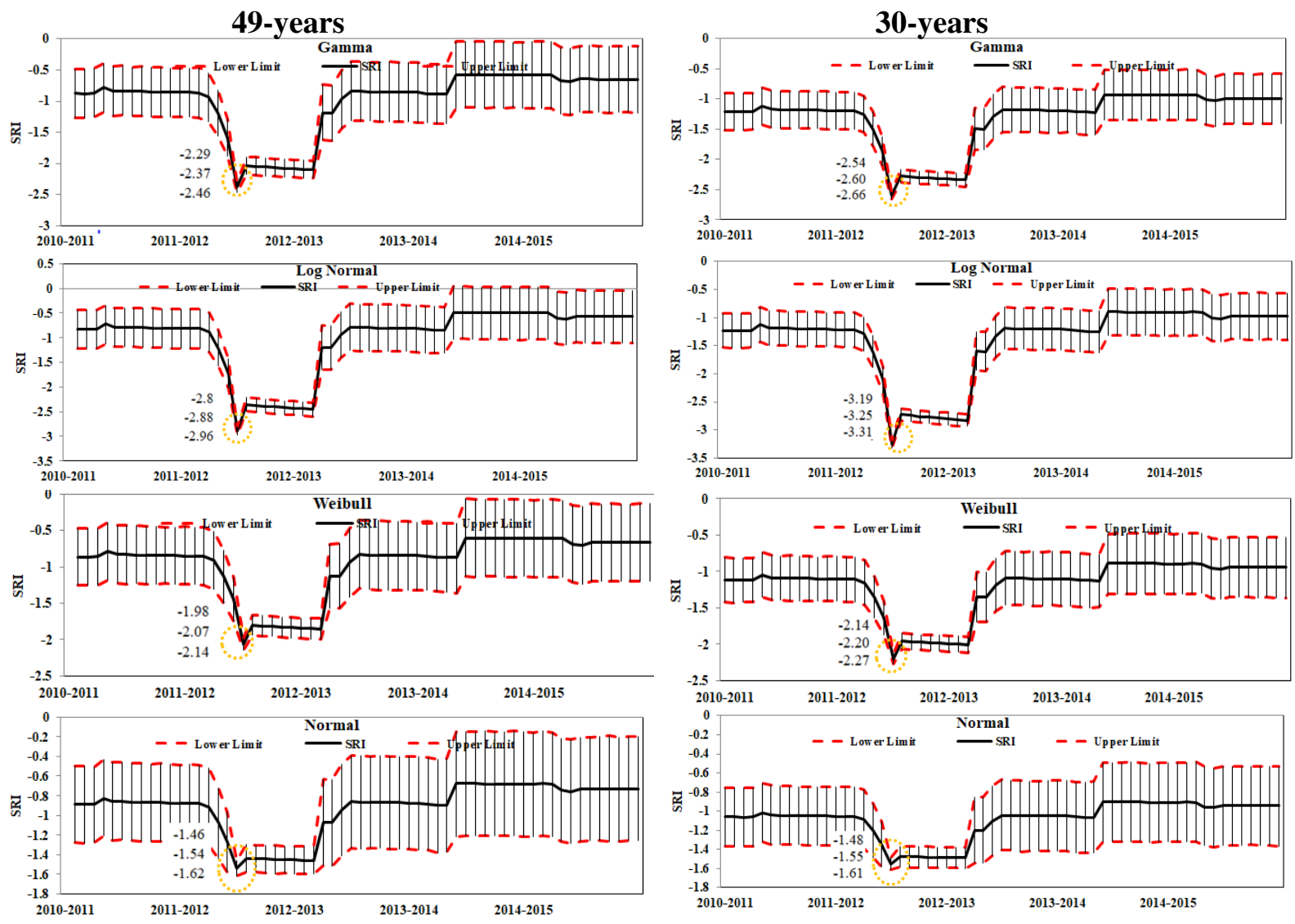

Figure 4- Time series 2010-2015 of SRI-48 and of the corresponding $95 \%$ confidence limits according to different underlying probability distributions (Gamma, Lognormal, Normal and Weibull) (Aug 2011-12)

\section{4-4 Assessment of maximum magnitude and duration of drought in studying distribution functions}

Drought intensity and duration for various time scales and distribution functions were calculated, after which the maximum intensity and the longest duration of drought were obtained for different functions, time scales, and record lengths. Figure 5 displays the maximum intensity and the longest duration of drought for 6 time scales, 4 distribution functions, and 2 time periods. A look at the duration bars showed that longer time scales were accompanied longer droughts. The longest duration for all time scales was related to the normal distribution except the 48-month time scale which was related to the lognormal distribution. Among the longer time scales (12-48 months) no notable difference was seen between two record lengths (30 and 49 years) for any of the distributions. A survey of maximum drought intensities showed that the increase in time scale led to the increase in 
drought magnitude. The highest drought magnitude was related to the lognormal distribution for all time scales, except for 24 month time scale and 30-year period which were related to the normal distribution. Generally the highest intensities were observed for 49-year period.

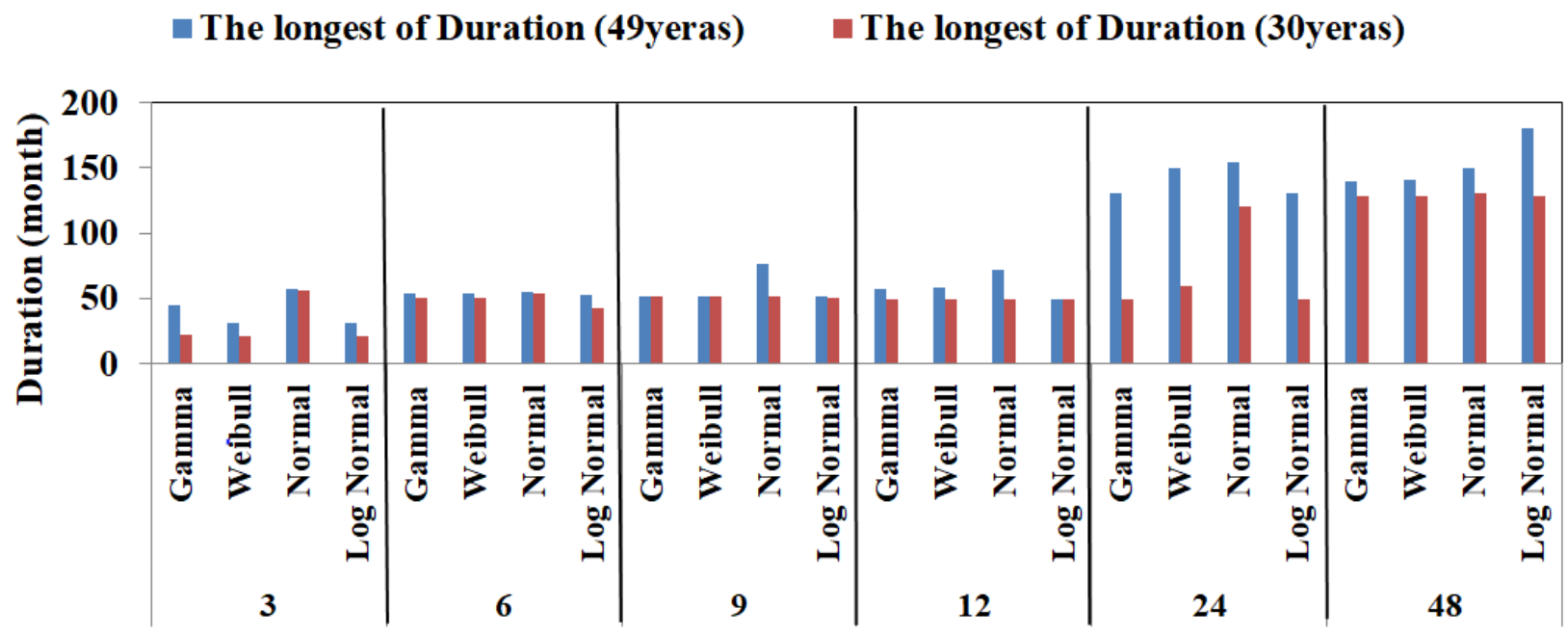

The highest of Magnitude (49years) $\quad$ The highest of Magnitude (30years)

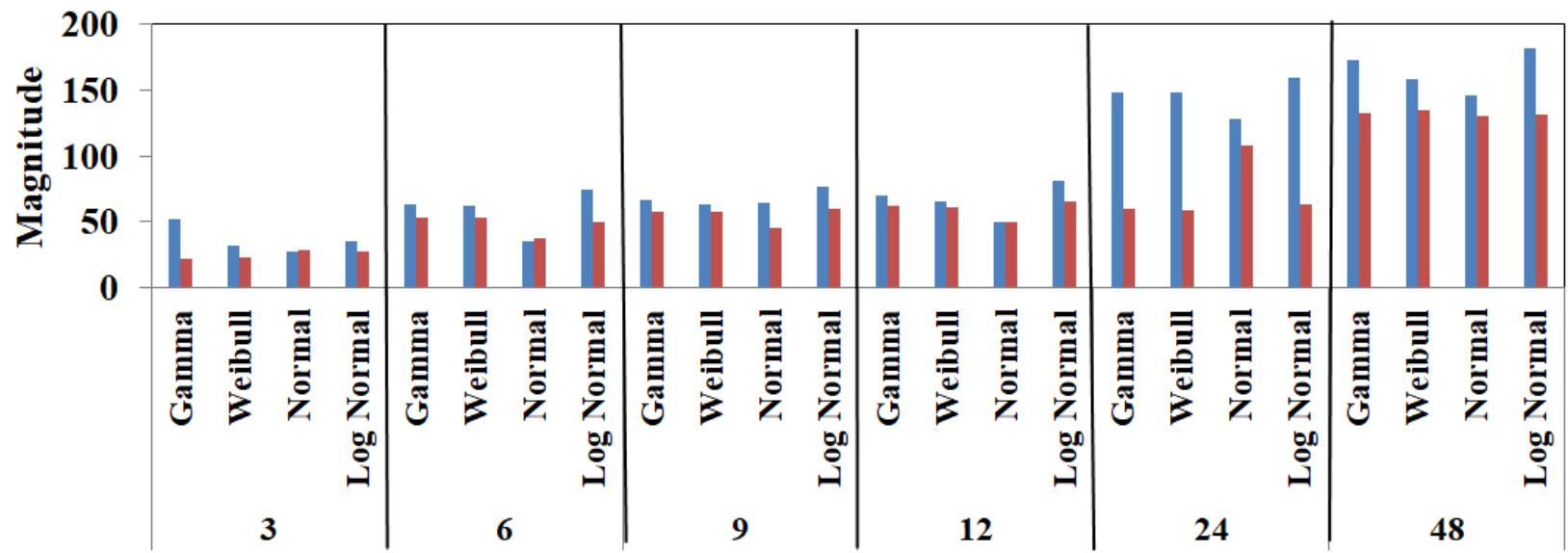

Figure 5. The highest magnitude and the longest duration for 30- and 49-year time periods, different time scales, and distribution functions

4-5 Uncertainty analysis of mean upper and lower limit differences in various distribution functions and record lengths

The average difference between upper and lower limits for different distribution functions and 3-48 month time scales was surveyed. As displayed in Figure (6), after an increment of time scale or record length, a reduction in uncertainty was detected. No significant difference was seen between four 
distribution functions. This result shows consistency with other studies in the literature (Hong et al. 2014; Hu et al. 2015; Vergni et al. 2015).
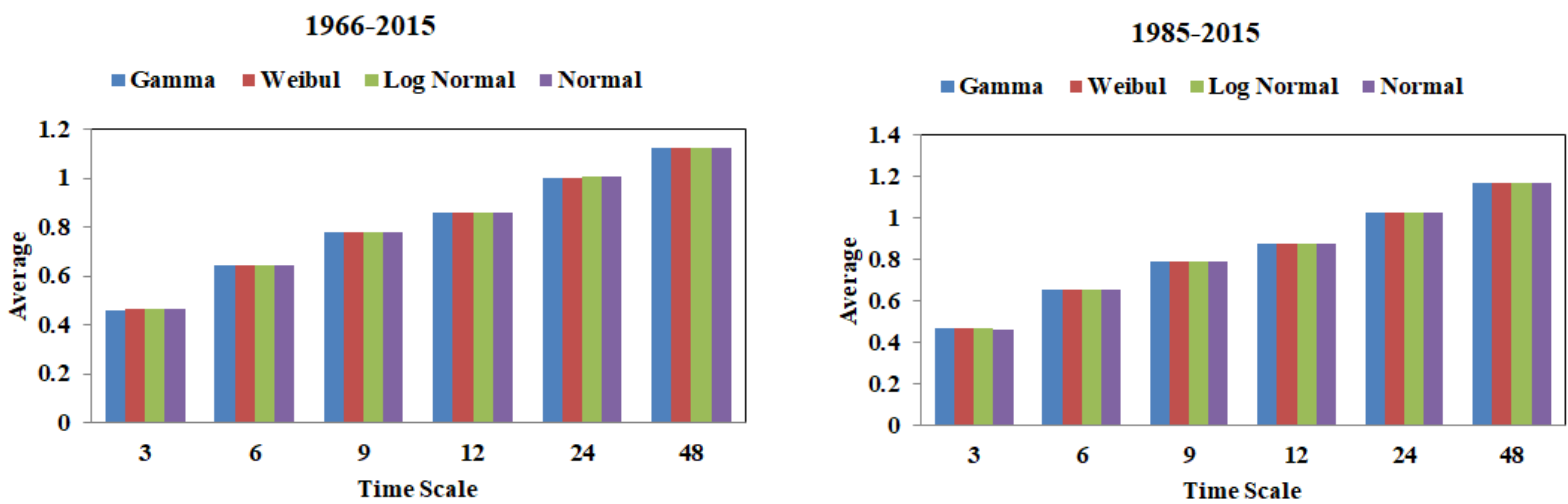

Fig. 6. Uncertatinty to upper and lower limit for average statistics in various distributions, time scales (3-48 months) and record lengths (49 and 30 years)

\section{Conclusion}

The current study was carried out to analyze uncertainty concerning two record lengths (30and 49-year), four distribution function types (Gamma, Normal, Lognormal, and Weibull) and 6 time scales $(3,6,9,12,24$, and 48 months). In order to calculate SRI, each of four distribution functions was fitted to discharge data separately; goodness-of-fit test and normality of SRI values were evaluated using K-S test and normality test, respectively. Afterwards, for "i"th month, "j"th year and "k"th time scale, 50000 stochastic data was generated by means of MCM and LHS, and uncertainty interval at 95\% confidence level was calculated.

Results of goodness-of-fit and normality tests for SRI revealed that the gamma and Weibull distributions had the best fitting and the normal distribution had the weakest fitting for both 30- and 49-year record lengths. Interpretation of the Gamma and Weibull parameters provides the possibility of understanding model properties and clustering the models performance for the various precipitation regimes. Unlike the normal and lognormal distribution that can intuitively evaluate the behavior of the model through its parameters, in these two models the effect of parameters $\sigma, \mu$ cannot be evaluated distinctly and 
should be considered simultaneous. The runoff data are not normally distributed. They are positive right skewed and Gamma and Weibull have better performance in these cases.

The maximum and minimum curves of upper and lower limits for the surveyed functions, time scales and record lengths showed that regardless of time scale, the highest and lowest values belonged to the normal and lognormal distributions, respectively. Further, the absolute values of mean and maximum increased with an increase in the time scale, while the absolute values of minimum decreased. The exception was the normal distribution for which the absolute values of minimum showed an increasing behavior with the increase in time scale.

Concerning all studied distribution functions and record lengths, the results manifested, that the highest duration and magnitude of drought related to the normal and lognormal distribution functions, respectively. Generally, gamma and Weibull distributions exhibited similar results.

A special regularity was found between the time scale length and confidence limits such that an increase in time scale resulted in an increment in the difference between upper and lower limits after which the confidence interval increased and the uncertainty of estimation decreased. Obviously, for time scales longer than 12 months, uncertainty decreased and similarity between various distribution functions increased.

\section{References}

Angelidis P, Maris F, Kotsovinos N, Hrissanthou V (2012) Computation of drought index SPI with alternative distribution functions. Water Resour Manag 26: 2453-2473.

Guttman N (1999) Accepting the standardized precipitation index: a calculation algorithm. J Am Water Resour Assoc 35: 311-322.

Guttman N (1998) Comparing the Palmer drought index and the standardized precipitation index. J Am Water Resour Assoc 34(1): 113-121.

Guttman NB (1994) On the sensitivity of sample L moments to sample size. J Clim 7: 1026-1029.

Guttman NB, Hosking JRM, Wallis JR (1994) Regional precipitation quantile values for the continental United States computed from Lmoments. J Clim 6(12): 2326-2340

Hong, X., Guo, S., Zhou, Y., Xiong, L., 2015. Uncertainties in assessing hydrological drought using streamflow drought index for the upper Yangtze River basin. Stoch Env. Res Risk Assess 1235-1247. doi:10.1007/s00477-014-0949-5

Hu, Y., Liang, Z., Liu, Y., Wang, J., Yao, L., Y Ning, 2015. Uncertainty analysis of SPI calculation and drought assessment based on the application of bootstrap. Int. J. Climatol. 1847-1857.

Lloyd-Hughes B, Saunders M (2002) A drought climatology for Europe. Int J Climatol 1571-1592. 
McKee T, Doesken J, Kleist J (1993) The relationship of drought frequency and duration to time scales. Presented at the Eight Conf on Applied Climatology, American Meteorological Society, Anaheim, 179-184.

Mishra A, Singh V (2010) A review of drought concepts. J Hydrol 202-216.

Naghettini M (2017) Fundamentals of Statistical Hydrology. Springer International Publishing, Switzerland.

Nalbantis I, Tsakiris G (2008) Assessment of hydrological drought revisited. Water Resour Manag 881-897.

Ropelewski C, Janowiak J, Halpert M (1985) The analysis and display of real time surface climate data. MonWeather Rev 1101-1106.

Shukla S, Wood A (2008) Use of a standardized runoff index for characterizing hydrologic drought. Geophys Res Lett 35: 1-8.

Sienz F, Bothe O, Fraedrich K (2012) Monitoring and quantifying future climate projections of dryness and wetness extremes: SPI bias. Hydrol Earth Syst Sci 2143-2157.

Vasiliades L, Loukas A, Liberis N (2011) A water balance derived drought index for Pinios River Basin, Greece. Water Resour Manag 25: 1087-1101.

Vergni L, Lena BD, Todisco F, Mannocchi F (2015) Uncertainty in drought monitoring by the Standardized Precipitation Index: the case study of the Abruzzo region (central Italy). Theor Appl Clim 1-14.

Vicente-Serrano S, Beguería S, López-Moreno J (2010) A multiscalar drought index sensitive to global warming: the standardized precipitation evapotranspiration index. J Clim 1696-1718.

Wilks D, Eggleston K (1992) Estimating monthly and seasonal precipitation distributions using the 30and 90-day outlooks. J Clim 252-259.

Wu H, Hayes M, Wilhite, D, Svoboda, F (2005) The effect of the length of record on the standardized precipitation index calculation. Int J Climatol 205-520.

Wu H, Svoboda, M, Hayes M, Wilhite, D, Wen F (20070 Appropriate application of the standardised precipitation index in arid locations and dry seasons. Int J Climatol 65-79. 
Figures

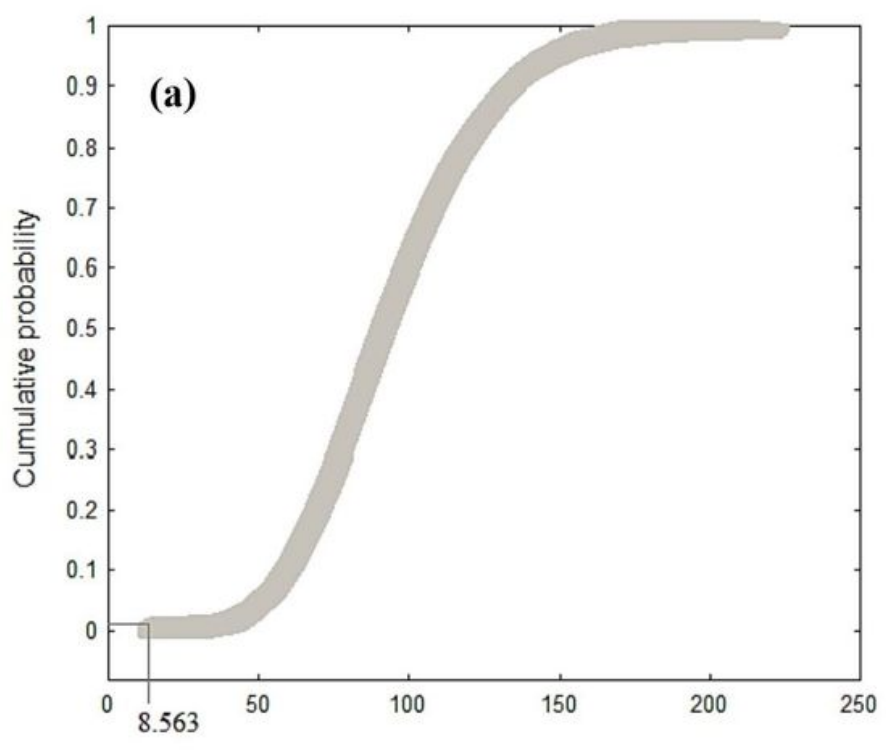

Discharge Cumulative precipitation

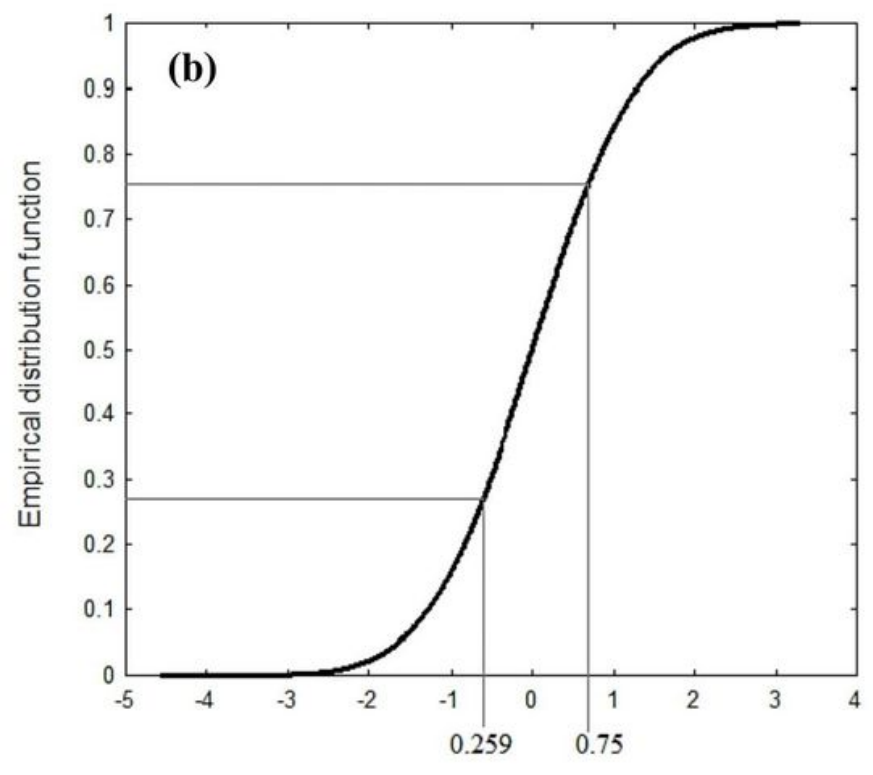

$(\mathrm{SRI}=-0.64) \quad(\mathrm{SRI}=0.69)$

SRICumulative probability

Figure 1

Representation of some steps required to obtain a confidence. 

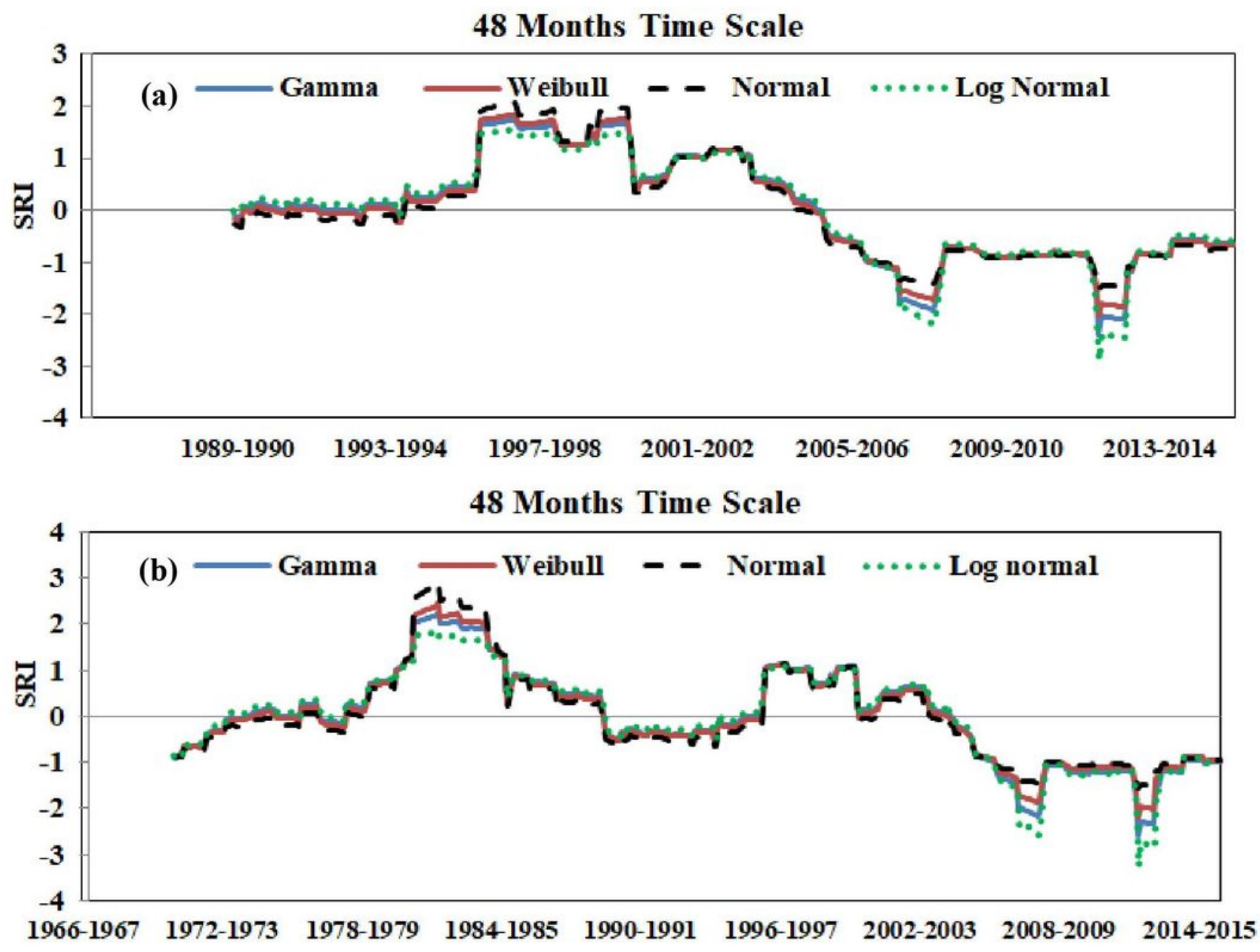

Figure 2

Drought monitoring using different probability distribution functions (a) 49 years and (b) 30 years 

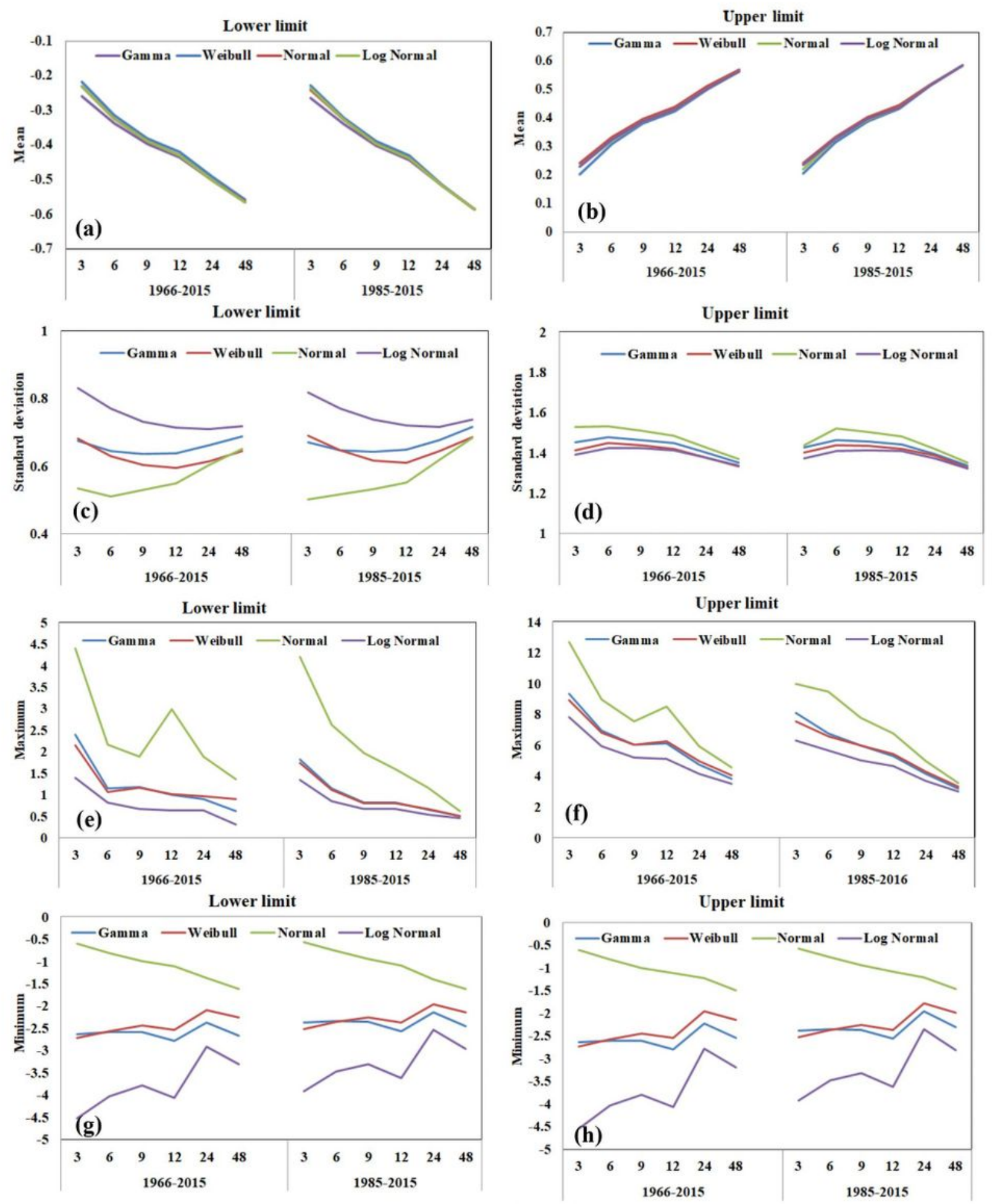

\section{Figure 3}

Average values of mean $(a, b)$ and standard deviation $(c, d)$ of maximum $(e, f)$ and minimum $(g, h)$ of the size of the SRI $90 \%$ confidence interval, varying the underlying probability distribution and the time scale $k$ on the basis of the data of all stations and the complete time series (1964-65 to 2014-15) and (19862015) 
49-years
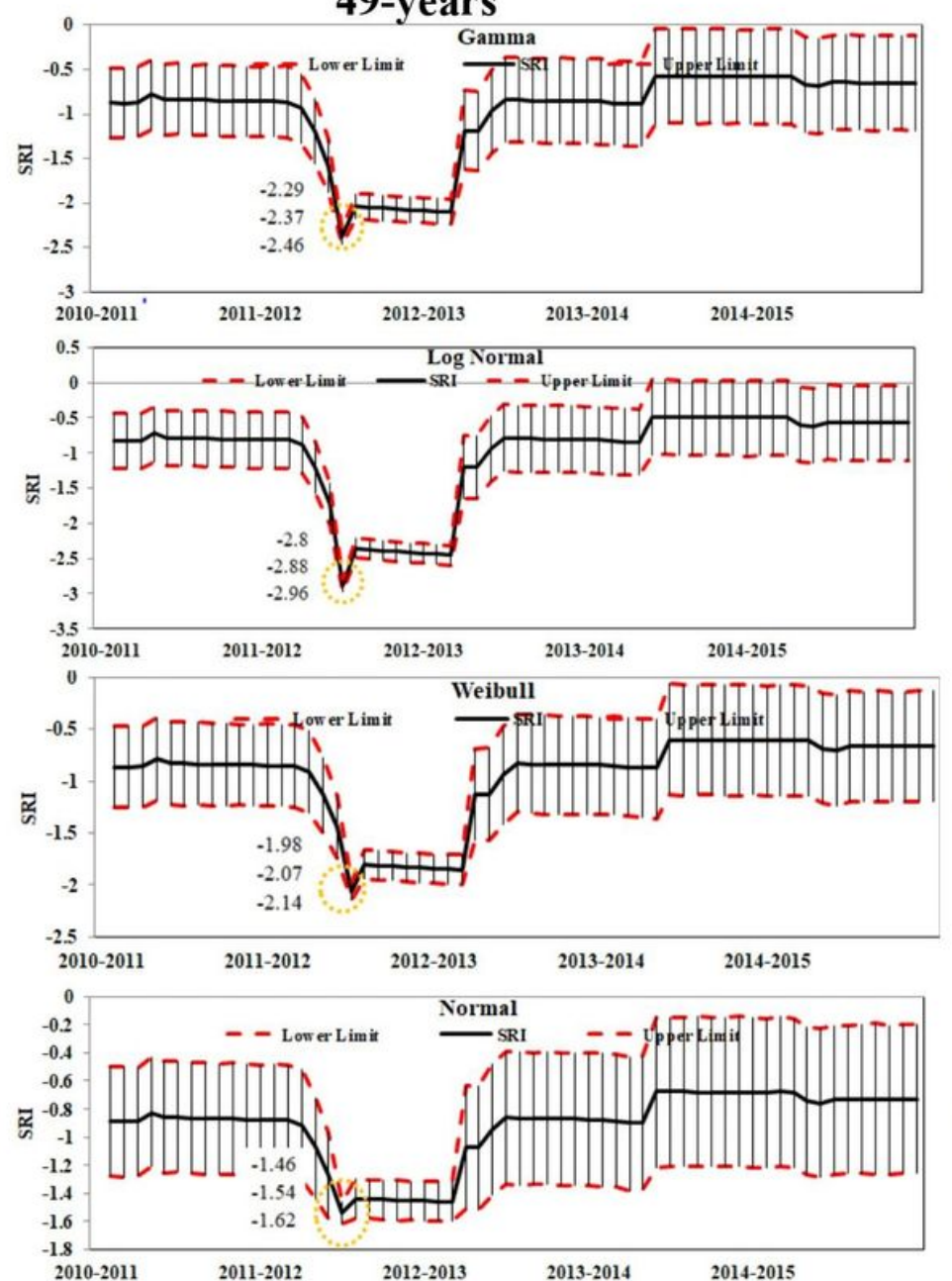

30-years
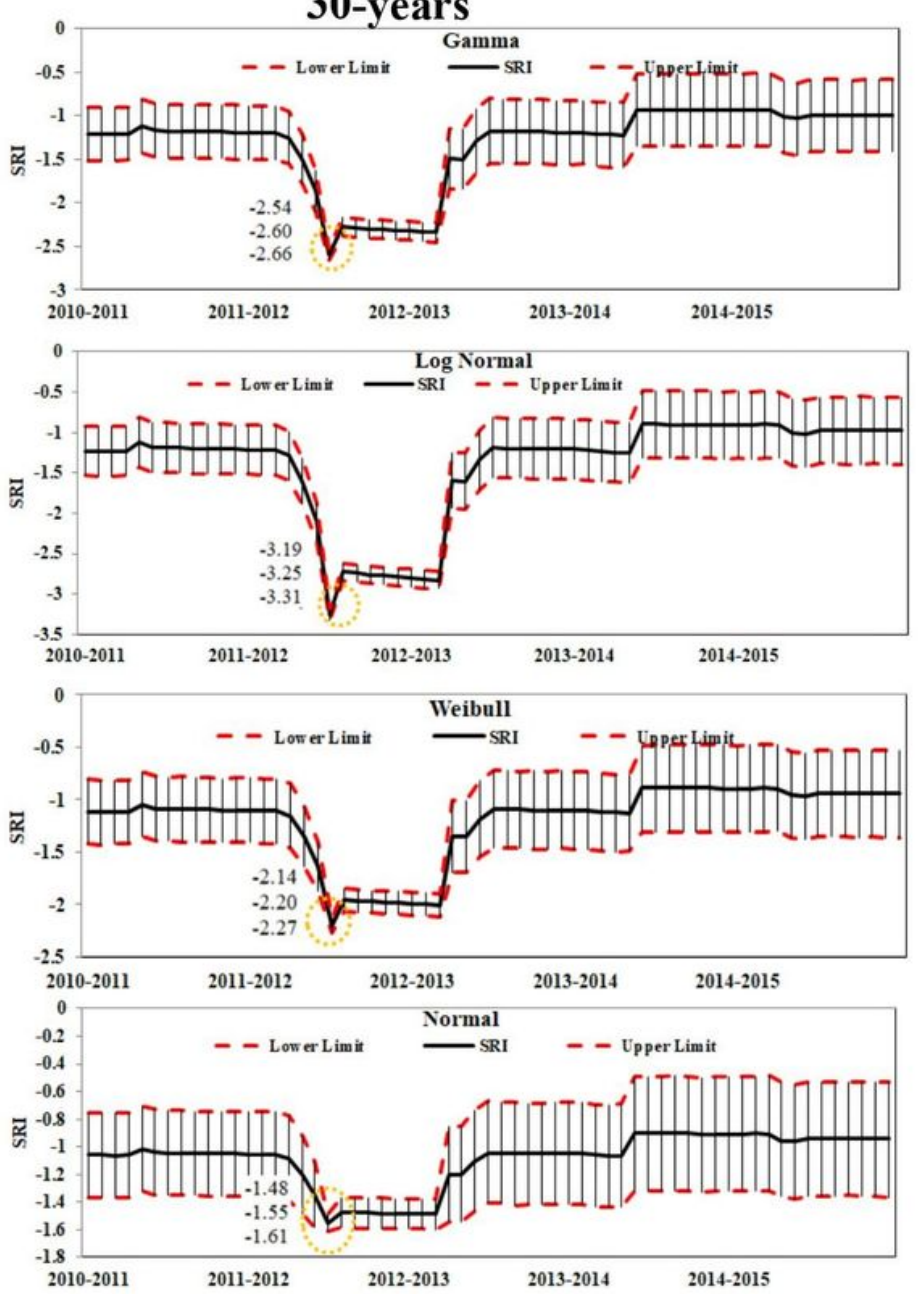

Figure 4

Time series 2010-2015 of SRI-48 and of the corresponding $95 \%$ confidence limits according to different underlying probability distributions (Gamma, Lognormal, Normal and Weibull) (Aug 2011-12) 
$\because$ The longest of Duration (49yeras) $\quad$ The longest of Duration (30yeras)

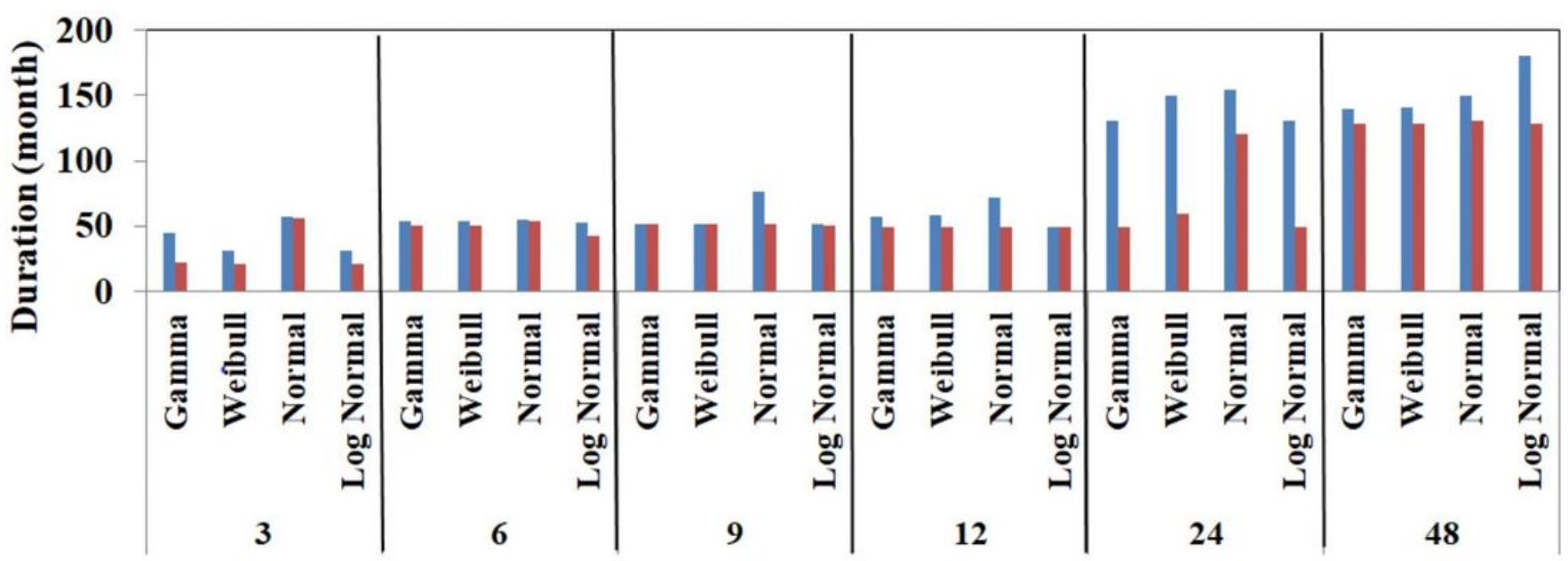

The highest of Magnitude (49years) $\quad$ The highest of Magnitude (30years)

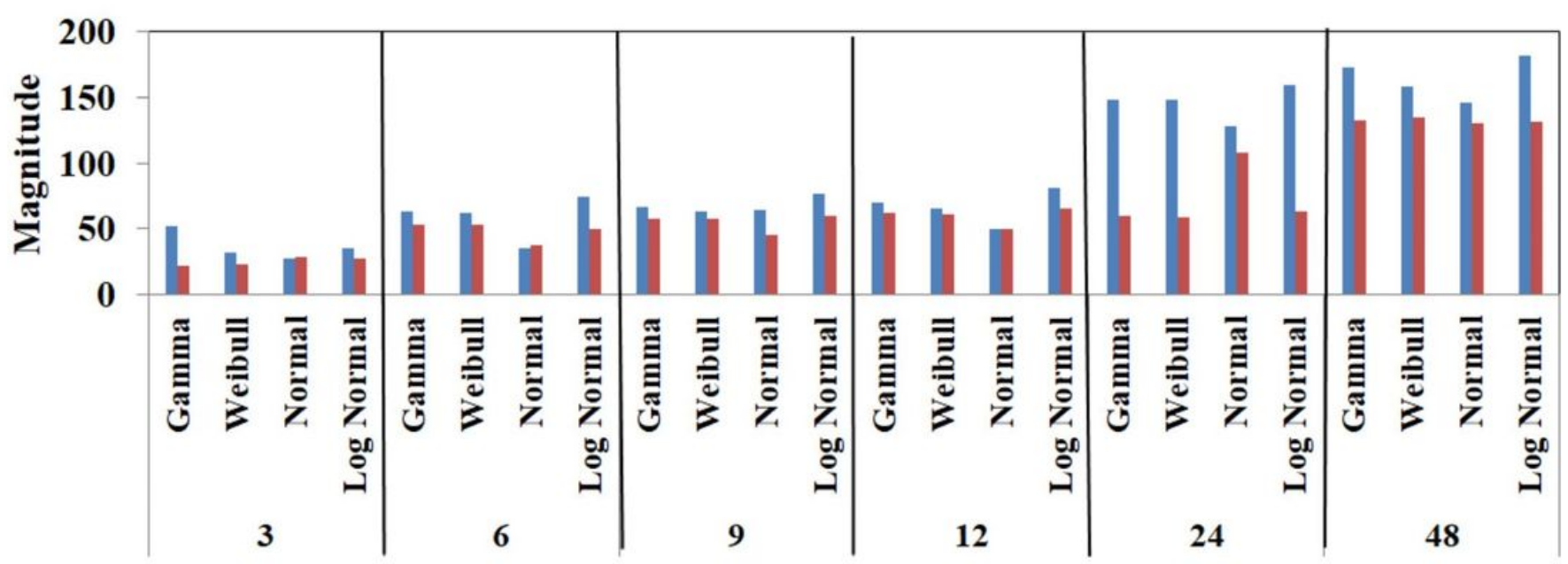

Figure 5

The highest magnitude and the longest duration for 30- and 49-year time periods, different time scales, and distribution functions

1966-2015

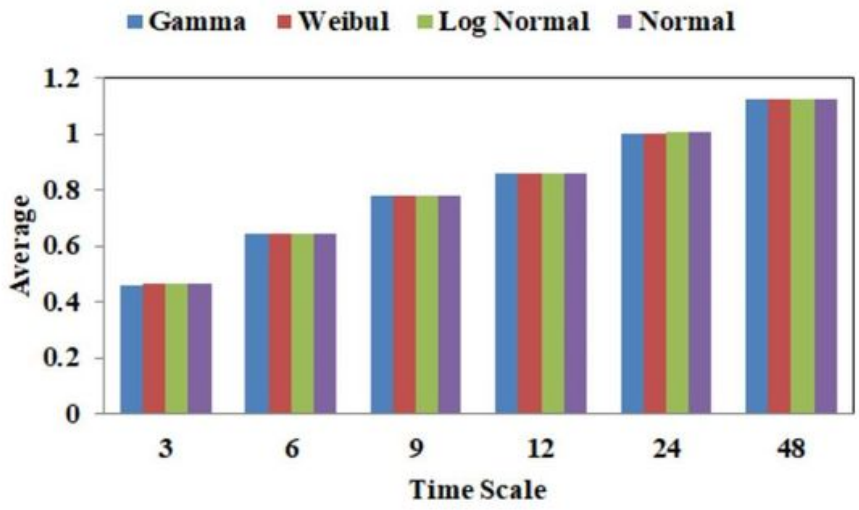

1985-2015

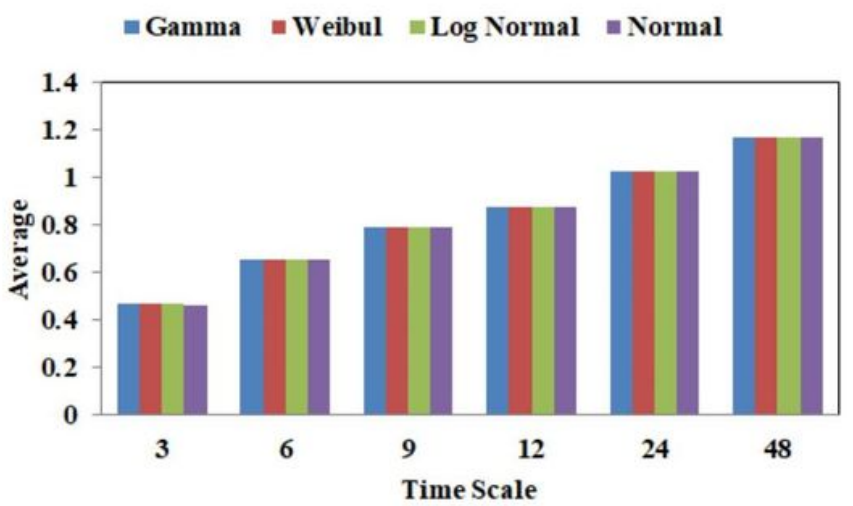


Figure 6

Uncertatinty to upper and lower limit for average statistics in various distributions, time scales (3-48 months) and record lengths (49 and 30 years) 